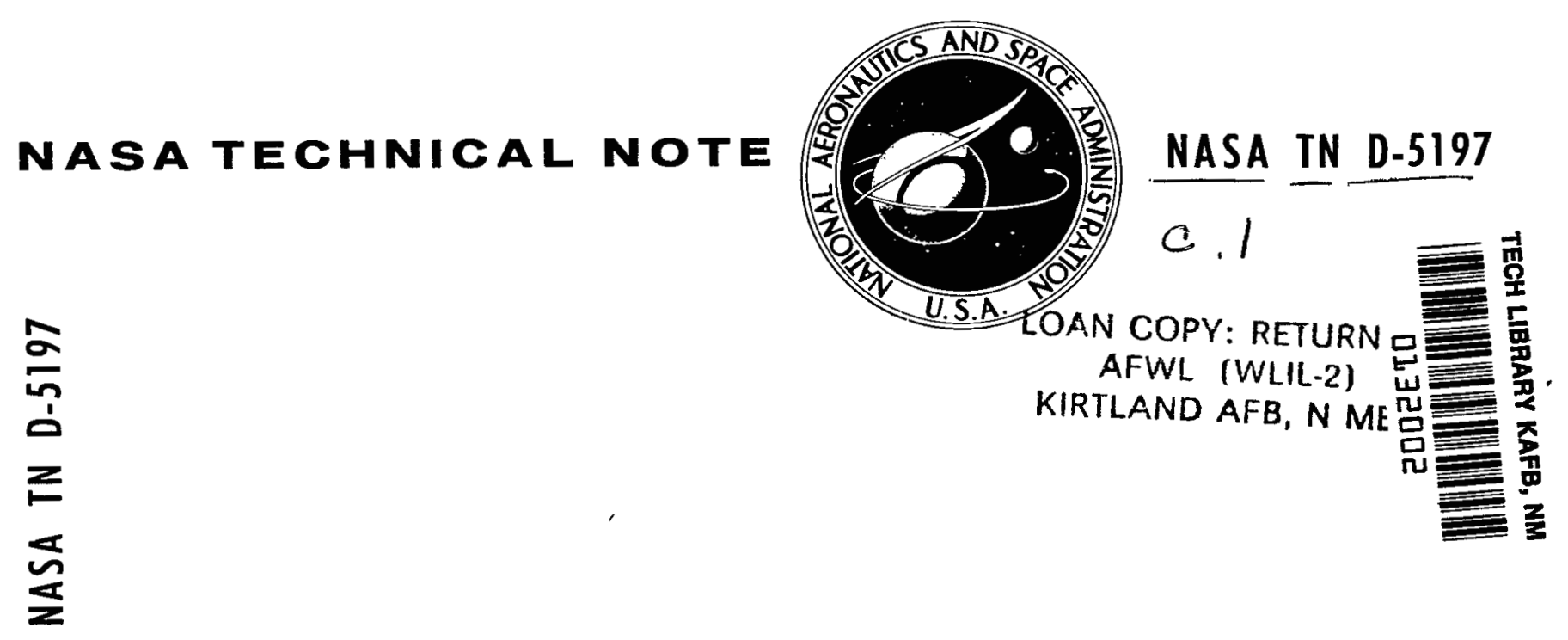

\title{
DETERMINATION OF OXYGEN IN LITHIUM BY THE VACUUM DISTILLATION METHOD
}

by Randall F. Gabn

Lewis Research Center

Cleveland, Obio

NATIONAL AERONAUTICS AND SPACE ADMINISTRATION - WASHINGTON, D. C. - MAY 1969 
DISTILLATION METHOD

By Randall F. Gahn

Lewis Research Center

Cleveland, Ohio 


\section{ABSTRACT}

The vacuum distillation method for determining oxygen in alkali metals was applied to lithium. In this method the nonvolatile inpurities, assumed to be lithium monoxide, are separated from the volatile lithium by heating the lithium sample in high vacuum. The alkalinity or the lithium content of the impurities is then converted to an oxygen concentration. Method reproducibility was determined at the 30 and $80 \mathrm{ppm}$ oxygen levels. Method accuracy was evaluated through quantitative oxygen additions and recoveries, estimation of the method blank, and characterization of the distillation residue from the Iithium-oxygen system. 


\section{DETERMINATION OF OXYGEN IN LITHIUM BY THE VACUUM \\ DISTILLATION METHOD \\ by Randall F. Gahn \\ Lewis Research Center}

\section{SUMMARY}

The vacuum distillation method for determining oxygen in alkali metals has been applied to lithium. In this method the nonvolatile impurities, assumed to be lithium monoxide, are separated from the volatile lithium by heating the lithium sample in high vacuum. The alkalinity or the lithium content of the impurities is then converted to an oxygen concentration.

Method reproducibility for five lithium series was found to be \pm 7 parts per million at the 30 parts per million oxygen level and \pm 22 parts per million at the 80 parts per million oxygen level. Method accuracy studies indicated (1) an average of 94 percent of the oxygen added to a lithium sample at the 138- and 276-microgram oxygen levels was recovered; (2) the method blank was found to be $0_{ \pm} 3$ micrograms oxygen over a lithium sample range of 0.3 to 1.2 grams; (3) the distillation residue, recovered from the lithiumoxygen system, was primarily lithium monoxide.

The results of this investigation indicate the vacuum distillation method is a promising technique for determining oxygen in lithium to levels less than 30 parts per million.

\section{INTRODUCTION}

Interest in the use of lithium as a heat-transfer fluid in nuclear reactor systems has created a need for improved analytical methods for determining impurities in lithium. Lithium is an attractive alkali metal for heat transfer because of its light weight, high heat capacity, wide liquidus range, and low vapor pressure. However, alkali metals in general are very corrosive when oxygen is present as an impurity, either in the alkali metal or in its container. Therefore, oxygen analysis of lithium used in corrosion testing programs is essential. 
Several methods for analyzing for oxygen in lithium are available, but they have numerous drawbacks such as complex procedure, side reactions, and high blanks. Proposed methods are the liquid ammonia method by Jaworowski, Potts, and Hobart (ref. 1); high-temperature fluorination technique by Goldberg (ref. 2); neutron activation by Bate and Leddicotte (ref. 3); and the method of oxide oxygen conversion to water followed by Karl Fischer titration proposed by Sax and Steinmetz (ref. 4).

Although all these methods have been useful, there is still need for a simple, economical method which can be used on a routine basis to determine oxygen in lithium to less than 30 parts per million. In the study reported herein, the vacuum distillation method, which has been applied to sodium and potassium, was extended to lithium at low oxygen levels. In this method the nonvolatile impurities, assumed to be lithium monoxide, are separated from the volatile lithium by heating a lithium sample in high vacuum. The alkalinity or the lithium content of the impurities is then converted to an oxygen concentration. The method was evaluated for reproducibility and accuracy.

\section{EXPERIMENTAL APPARATUS AND PROCEDURE}

\section{Lithium Samples}

The five lithium series used in these studies were purified by two different techniques - distillation and hot gettering. The distilled lithium was designated as Series I and II; the hot-gettered lithium was designated as Series III, IV, and V.

The lithium for each series was transferred from 454-gram stainless-steel containers to 0.95 centimeter in diameter by 17.1 centimeters long stainless-steel tubes and then stored in vacuum until used. For all analyses, samples were extruded from the sample tubes.

\section{Vacuum Distillation}

Apparatus. - The vacuum distillation apparatus shown in figure 1 consists of an extruder section, a pressure monitoring section, and a vaporization section. The apparatus is fabricated of stainless steel except for the distillation section, which is made of glass. The middle section is connected to a vacuum diffusion pump through a liquid nitrogen cold trap. The vaporization unit, made of heat-resistant glass, is connected to the metal system with an O-ring joint. Either one crucible, 2.54 centimeters in diameter by 2.54 centimeters long, or three crucibles, each 1.27 centimeters in diameter by 2.54 centimeters long, can be placed in the stainless-steel crucible holder. Tantalum 


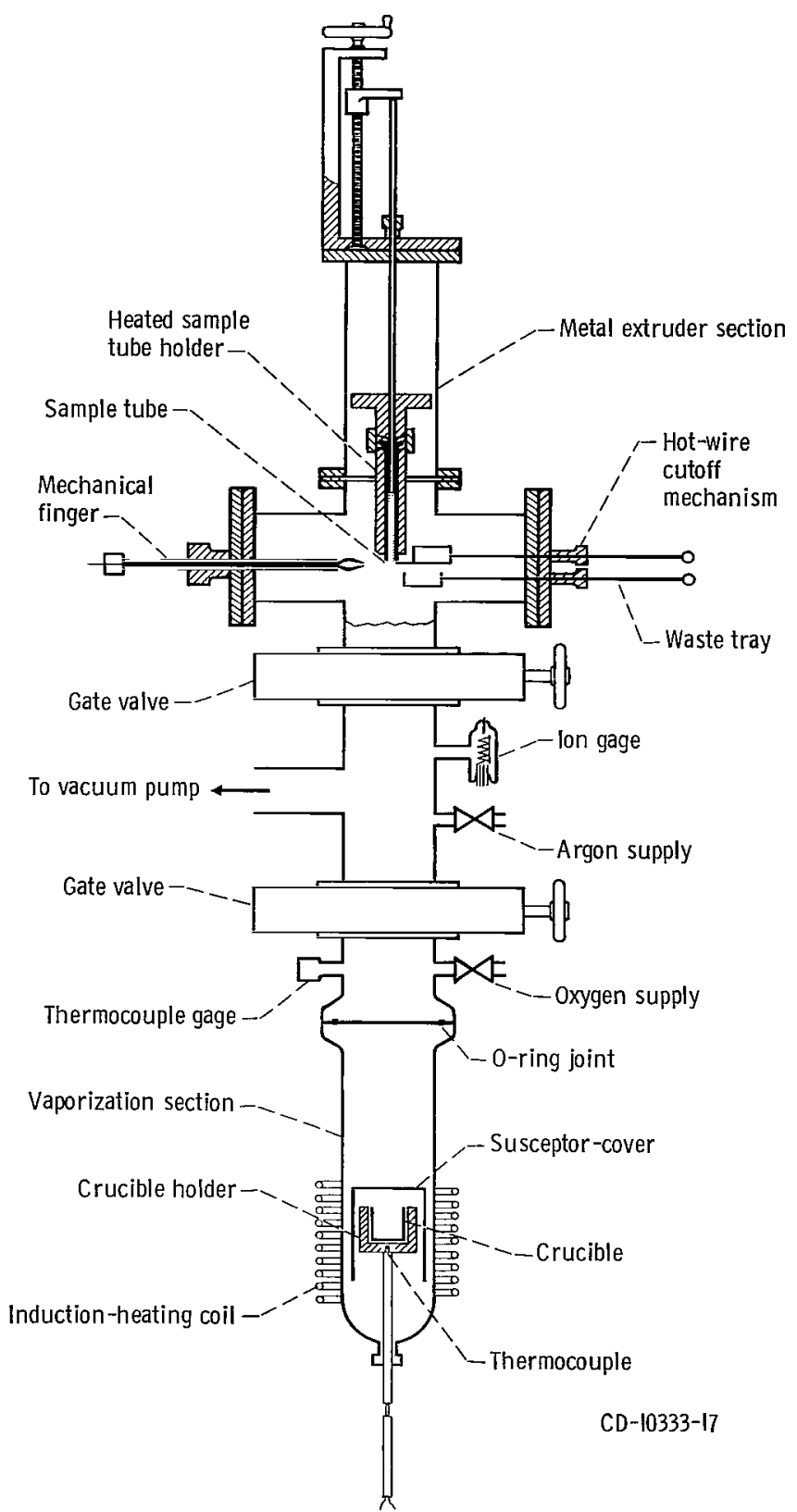

Figure 1. - Analytical apparatus for vacuum distillation of alkali metals. 
or molybdenum crucibles were used. A niobium foil-covered tantalum susceptor-cover is placed over the crucible holder. All operations within the apparatus are carried out under a pressure of $7 \times 10^{-6}$ torr or less. Wilson seals are employed to permit manipulation in vacuum of the various moving parts (shown in fig. 1), which are the extruder piston, hot-wire cutoff mechanism, waste tray, mechanical finger, and crucible holder. A $2 \frac{1}{2}$-kilowatt induction heater is used to heat the susceptor-cover. The crucible temperature, taken as that of the crucible holder, is measured in the base of the crucible holder with a Chromel-Alumel thermocouple.

Procedure. - The extreme reactivity of lithium with oxygen, nitrogen, and moisture makes it essential that the lithium be protected from atmospheric contamination during sampling and distillation. In this work all operations were performed in high vacuum.

A sample tube filled with lithium was placed in the extruder, and the extruder section was evacuated. The crucible assembly was placed inside the glass envelope, and the envelope was connected to the vacuum system and evacuated. The crucible was then outgassed at $750^{\circ}$ to $800^{\circ} \mathrm{C}$ for at least $1 / 2$ hour. Following the outgassing period, the crucible was raised to the extruder section, and the susceptor-cover was removed with the mechanical finger. When the crucible had cooled to room temperature and an operable vacuum of $7 \times 10^{-6}$ torr or less was obtained, the analysis was begun.

The lithium sample tube holder was heated to $66^{\circ} \mathrm{C}$ to soften the lithium, which was then extruded into the crucible and cut off with the hot-wire cutoff mechanism. The susceptor-cover was placed over the crucible, and the crucible was lowered to the distillation section. Heat was applied to the susceptor-cover while the glass envelope was externally cooled by means of an air blower. In the temperature range $350^{\circ}$ to $400^{\circ} \mathrm{C}$, vaporization of lithium could be observed. The temperature was increased to $700^{\circ} \mathrm{C}$ at the rate of approximately $5^{\circ} \mathrm{C}$ per minute. The crucible was held at the final temperature for at least 1 hour. Condensation of the lithium vapor took place on the inner surface of the glass envelope. The susceptor-cover acted as a baffle directing thelithium vapor to the lower half of the glass chamber.

At the completion of the distillation the crucible was allowed to cool to room temperature, the glass chamber was backfilled with argon, and the crucible was removed. The crucible was rinsed with distilled water and the basic solution was titrated with 0.010 normal sulfuric acid $\left(\mathrm{H}_{2} \mathrm{SO}_{4}\right)$ to the methyl red end point. In some cases following titration, the solution was analyzed for lithium by flame photometry.

The lithium sample weight was calculated by measuring displacement of the extruder piston. The piston was calibrated by extruding lithium samples of varying size (measured by the number of turns of the extruder handle), dissolving the lithium in water, and titrating an aliquot of the basic solution with 1.0 normal $\mathrm{H}_{2} \mathrm{SO}_{4}$ to the methyl red end point. Reproducibility for the sample weight determined by this technique is \pm 2 percent. 


\section{Quantitative 0xygen Additions to Lithium}

Quantitative oxygen additions to lithium samples were made in the distillation apparatus. Following the lithium sampling, the crucible and lithium (without the susceptorcover) was lowered to the distillation section. The lithium in the crucible was heated to $300^{\circ} \mathrm{C}$, and the distillation chamber was valved off from the rest of the apparatus. A standard volume of gaseous oxygen was admitted and allowed to react with the lithium. Quantitative reaction of the oxygen with the lithium was observed with a thermocouple gage on the distillation section; that is, the pressure after the reaction was the same as before the oxygen addition. After the uptake of oxygen, the distillation section was opened to the vacuum system, and the crucible was raised to the extruder where the susceptorcover was put in place. The crucible assembly was then lowered to the distillation section and the lithium distillation accomplished as previously described.

\section{Distillation Residue Characterization Studies}

The nature of the compound obtained from the lithium-oxygen system subjected to the distillation conditions was determined by adding oxygen (nonquantitatively, in the range of 10 to $50 \mathrm{mg}$ ) to a molten lithium sample, performing the normal distillation procedure and then recovering the residue in an uncontaminated condition for $\mathrm{X}$-ray diffraction and chemical analysis. The technique for recovering and identifying compounds of this nature is described in reference 5.

Oxygen was added to the lithium by submerging the tip of a 1.6-millimeter-diameter stainless-steel tube from the oxygen source into the molten lithium. Oxygen was bubbled through the lithium at a dynamic vacuum system pressure of $2 \times 10^{-4}$ torr. No quantitative measure of oxygen was made. Following the reaction period a normal distillation run was made and the residue was recovered for analysis as described in reference 5.

\section{RESULTS AND DISCUSSION}

The tests described in this report were made to prove the feasibility of the vacuum distillation technique for the determination of oxygen in lithium. To do this the reproducibility and accuracy of the method had to be demonstrated.

\section{Reproducibility}

Data for method reproducibility are given for five lithium series in table I. Oxygen 
TABLE I. - METHOD REPRODUCIBILITY

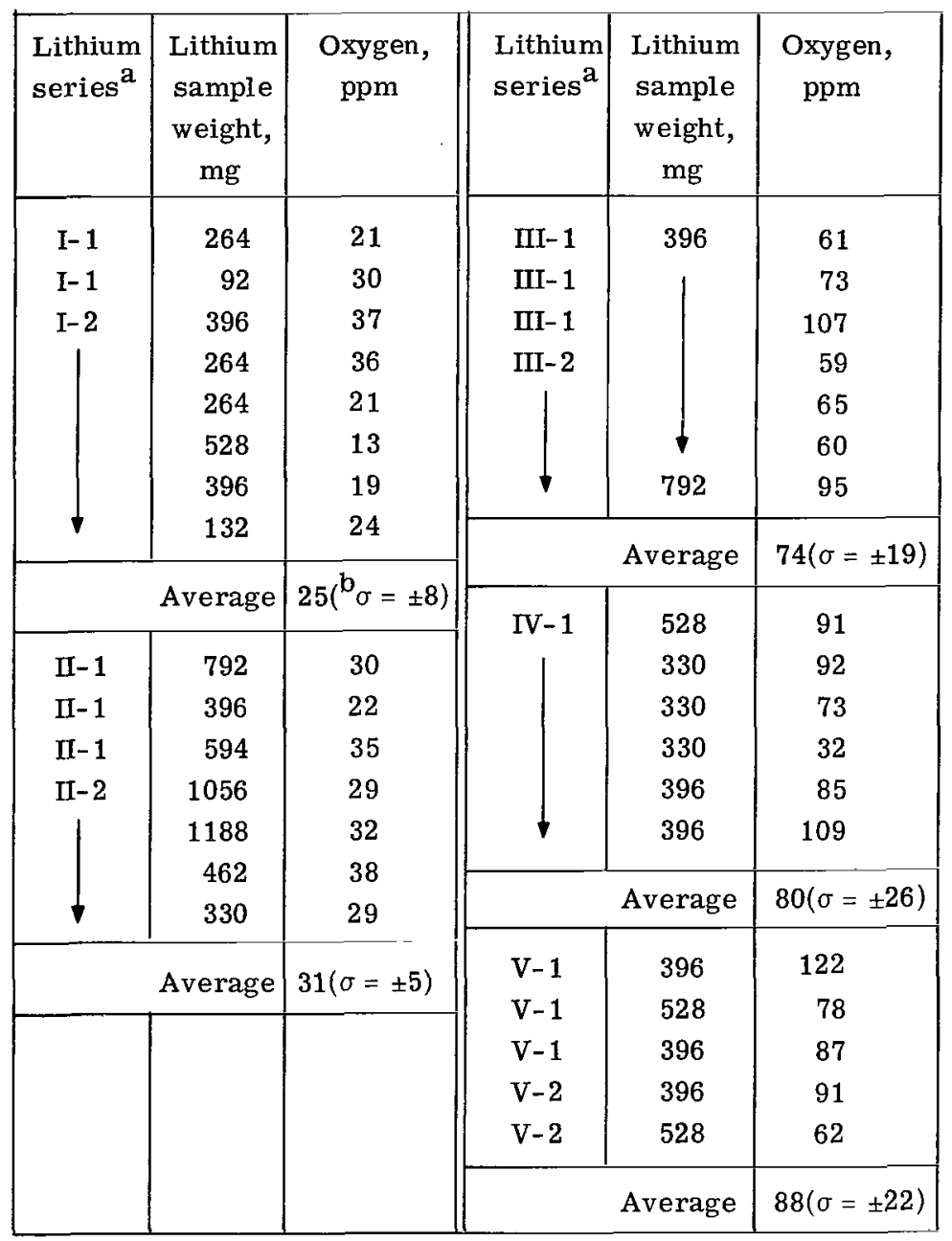

${ }^{\mathrm{a}}$ Series I and II lithium were purified by distiflation. Series III, IV, and V lithium were purified by hot-gettering.

$\mathrm{b}_{\sigma}=$ Standard deviation.

results for Series I and II lithium (purified by distillation) were $25 \pm 8$ and $31_{ \pm} 5$ parts per million oxygen, respectively. Oxygen results for Series III, IV, and V lithium (purified by hot-gettering) were $74 \pm 19,80 \pm 26$, and $88 \pm 22$ parts per million oxygen, respectively. The oxygen concentrations were calculated assuming the distillation residue was completely lithium monoxide $\left(\mathrm{Li}_{2} \mathrm{O}\right)$.

It should be noted that this method can be used to make multiple simultaneous determinations on replicate samples. In this work, as many as three simultaneous determinations were made. The upper limit for the number of simultaneous determinations is determined by the physical size of the particular system used. 


\section{Accuracy}

Three types of tests were made to determine the accuracy of the vacuum distillation technique: estimation of the method blank, quantitative addition and recovery of oxygen, and identification or characterization of the distillation residue from the lithiumoxygen system.

The method blank for the distillation method was estimated for Series II lithium by plotting the oxygen values against sample size (fig. 2) for sample weights varying from

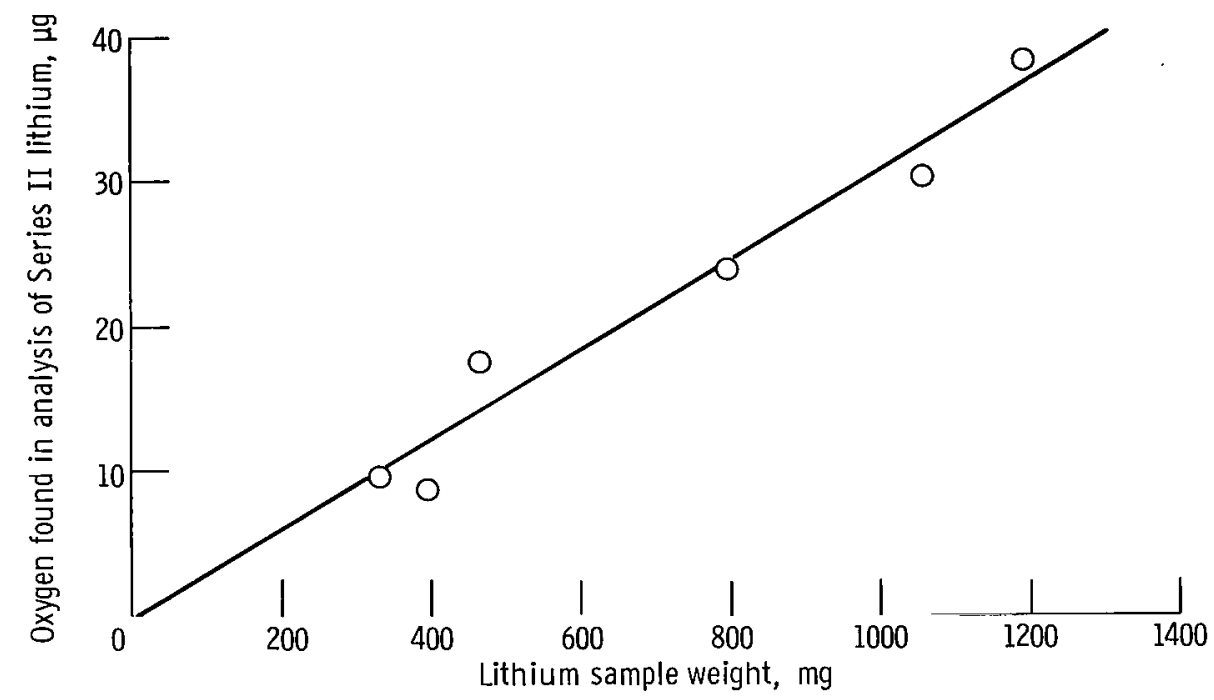

Figure 2. - Method blank determination. Method blank = ordinate intercept = $0 \pm 3$ micrograms oxygen.

about 0.3 to 1.2 grams. The intercept of the least-squares line at zero sample weight yielded a blank value of $0 \pm 3$ micrograms oxygen. Even though a zero blank was obtained, the standard deviation of this value is evidence that the zero blank was fortuitous. There is undoubtedly some oxygen pickup during the distillation procedure which should be reflected in the blank. For a more critical blank determination, additional samples over a larger sample weight range should be analyzed. However, even if the blank is not zero but of the order of several micrograms oxygen, it is still insignificant if large samples (at least $1 \mathrm{~g}$ ) are used in the analysis.

Results of quantitative oxygen additions to lithium to evaluate method accuracy are given in table $I I$. The alkalinity results obtained by titration and the lithium results found by flame photometric analysis of the alkaline solutions were converted to an equivalent oxygen value. The average oxygen value was compared with the sum of the oxygen present initially and the oxygen added. Oxygen recoveries were between 89 and 98 percent, averaging about 94 percent. 
TABLE II. - RECOVERY OF QUANTITATIVE OXYGEN ADDITIONS

TO LITHIUM

\begin{tabular}{|c|c|c|c|c|c|c|c|}
\hline \multirow{3}{*}{$\begin{array}{c}\text { Lithium } \\
\text { series }\end{array}$} & \multirow{3}{*}{$\begin{array}{c}\text { Lithium } \\
\text { sample } \\
\text { weight, } \\
\text { mg }\end{array}$} & \multicolumn{5}{|c|}{ Oxygen, $\mu \mathrm{g}$} & \multirow{3}{*}{$\begin{array}{l}\text { Percent } \\
\text { recovery }\end{array}$} \\
\hline & & \multirow[t]{2}{*}{ Present } & \multirow[t]{2}{*}{ Added } & \multicolumn{3}{|c|}{ Found $^{\mathrm{a}}$} & \\
\hline & & & & $\begin{array}{l}\text { Titra- } \\
\text { tion }\end{array}$ & $\begin{array}{c}\text { Flame } \\
\text { photom- } \\
\text { etry }\end{array}$ & Average & \\
\hline I & 330 & 8 & 138 & 134 & 139 & 137 & 94 \\
\hline V & 330 & 29 & 138 & 143 & 153 & 148 & 89 \\
\hline V & 330 & 29 & 276 & 298 & 302 & 300 & 98 \\
\hline${ }^{b}$ VI & 330 & 19 & 276 & 280 & 288 & 284 & 96 \\
\hline
\end{tabular}

${ }^{\mathrm{a}} \mathrm{Cal}$ culated assuming residue to be $\mathrm{Li}_{2} \mathrm{O}$.

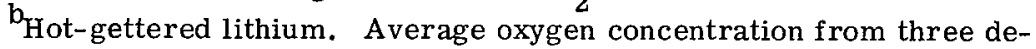
terminations was $58 \mathrm{ppm}$.

TABLE III. - CHEMICAL ANALYSIS OF

DISTILLATION RESIDUE

\begin{tabular}{|c|c|c|c|c|}
\hline \multirow[t]{2}{*}{ Run } & \multirow{2}{*}{$\begin{array}{l}\text { Weight, } \\
\text { mg }\end{array}$} & \multicolumn{2}{|c|}{ Lithium found, mg } & \multirow{2}{*}{$\begin{array}{c}\text { Lithium } \\
\text { content } \\
\text { (theoretical), } \\
\mathrm{mg}\end{array}$} \\
\hline & & $\begin{array}{c}\text { Flame } \\
\text { photometry }\end{array}$ & Titration $^{\mathrm{a}}$ & \\
\hline 1 & 84.2 & 37.5 & 38.4 & 39.1 \\
\hline 2 & 14.9 & 7.0 & 6.8 & 6.9 \\
\hline 3 & 31.3 & 14.0 & 14.1 & 14.5 \\
\hline 4 & 93.2 & 39.0 & 41.8 & 43.3 \\
\hline 5 & 40.1 & 18.0 & 18.3 & 18.6 \\
\hline
\end{tabular}

${ }^{a}$ Calculated assuming residue to be $\mathrm{Li}_{2} \mathrm{O}$.

Chemical analysis results of the lithium-oxygen system distillation residue characterization studies are shown in table III. The alkalinity results obtained by titration were converted to lithium values. Lithium values found by both flame photometry and titration are compared with the theoretical lithium values. The good agreement of results indicates the residue to be $\mathrm{Li}_{2} \mathrm{O}$.

$\mathrm{X}$-ray diffraction patterns of the residue were obtained, and a typical pattern is compared with that of $\mathrm{Li}_{2} \mathrm{O}$ (ref. 6) in table IV. The good agreement further confirms that the residue is primarily $\mathrm{Li}_{2} \mathrm{O}$. 
TABLE IV. - X-RAY DIFFRACTION ANALYSIS OF

DISTILLATION RESLUE

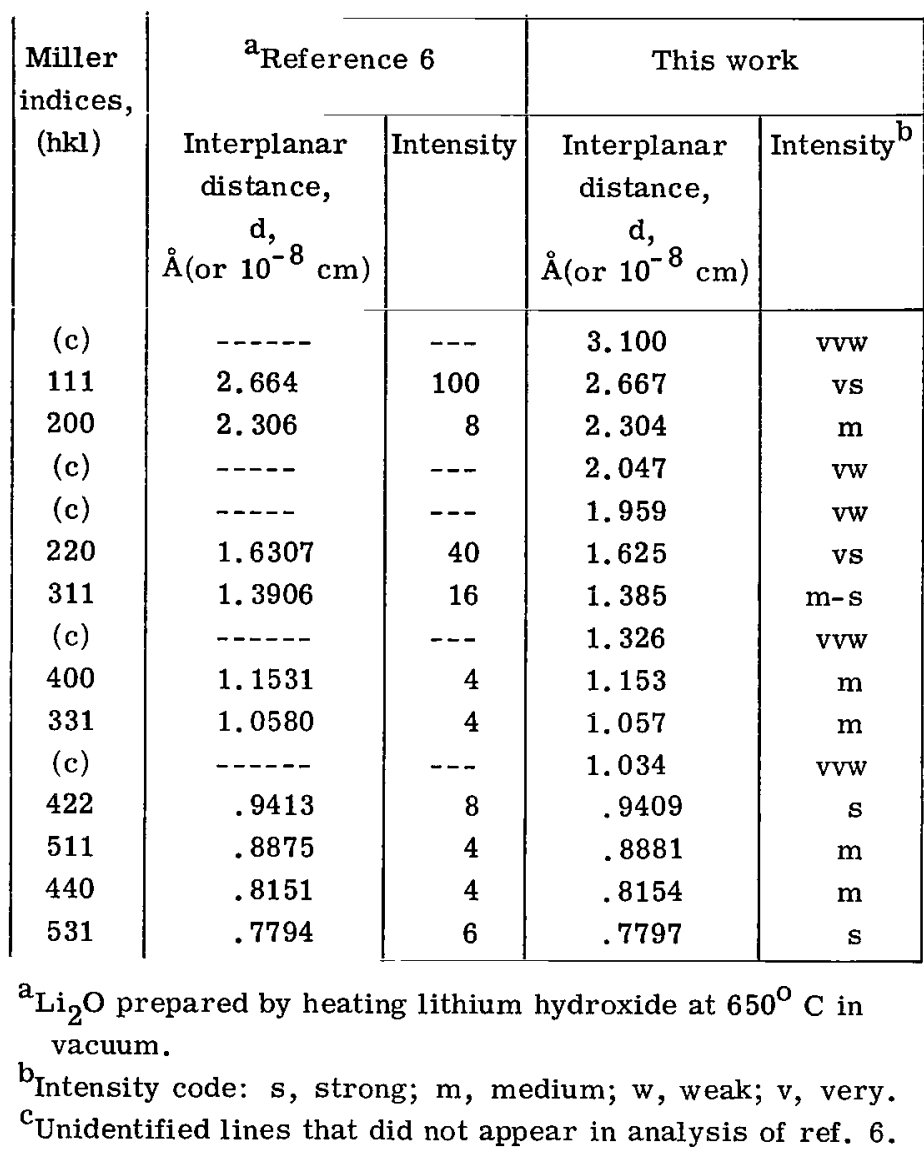

The results of the distillation residue characterization studies indicate, however, that the residue may not be pure $\mathrm{Li}_{2} \mathrm{O}$, but probably contains a very small amount of a second phase. Evidence of a second phase is seen from the five unidentified lines on the $\mathrm{X}$-ray diffraction pattern and from the chemical analysis of the residue as indicated in table III.

The quantitative addition of oxygen and the recovery of $\mathrm{Li}_{2} \mathrm{O}$ as the nonvolatile product shows that preparation of low-oxygen standard-1ithium samples can be made for the calibration of the distillation method. It should be noted, however, that the lithium used in these studies was of high purity and the effect of other elements, such as the interstitial elements or the alkali and alkaline earth metals, on the oxygen determination has not been established.

\section{SUMMARY OF RESULTS}

The vacuum distillation method for determining oxygen in alkali metals was applied to lithium. The method was evaluated for reproducibility and accuracy. 
In this method, the lithium sample is heated in a molybdenum or tantalum crucible in vacuum to $700^{\circ} \mathrm{C}$ for several hours to distill off the lithium. After cooling, the crucible is rinsed with water and the solution analyzed for alkalinity and in some cases for lithium content. The oxygen concentration is calculated assuming the distillation residue is entirely lithium monoxide.

Method reproducibility, as determined from 33 determinations on five lithium series, was found to be \pm 7 parts per million at the 30 parts per million oxygen level and \pm 22 parts per million oxygen at the 80 parts per million oxygen level.

Method accuracy was evaluated by the following tests: (1) the quantitative addition and recovery of oxygen, (2) the estimation of the method blank, and (3) the characterization of the lithium-oxygen system distillation residue. Quantitative additions of gaseous oxygen (138 and $276 \mu \mathrm{g}$ levels) to $0.33 \mathrm{gram}$ molten lithium samples indicated that an average of 94 percent of the oxygen was recovered following the distillation procedure. The oxygen addition technique described provides a method for preparing low-oxygen standard lithium samples for calibration of the method. The method blank was estimated as $0_{ \pm} 3$ micrograms oxygen. Although a zero blank is unlikely, the value was insignificant at the oxygen levels reported. Chemical and $\mathrm{X}$-ray diffraction analyses indicate the residue was primarily lithium monoxide.

The results of this investigation indicate that the vacuum distillation method is a promising method for determining oxygen in lithium to less than 30 parts per million. The effect of other impurities in the lithium, such as the interstitial elements or the alkali and alkaline earth metals, on the oxygen determination has not been established. The method is not complicated by purity or reagents, tedious procedures, or high blanks, as were previous methods.

Lewis Research Center,

National Aeronautics and Space Administration, Cleveland, Ohio, February 14, 1969, 129-03-03-01-22.

\section{REFERENCES}

1. Jaworowski, R. J.; Potts, J. R.; and Hobart, E. W.: The Determination of Oxygen in Lithium. Anal. Chem., vol. 35, no. 9, Aug. 1963, pp. 1275-1279.

2. Goldberg, Gerald: Determination of Oxides and Nitrides in Lithium Metal by HighTemperature Fluorination with Potassium Bromotetrafluoride. Anal. Chem., vol. 34, no. 10, Sept. 1962, pp. 1343-1344. 
3. Bate, L. C.; and Leddicote, G. W.: Analytical Chemistry Division Annual Progress Report for Period Ending December 31, 1957. Rep. ORNL-2453, Oak Ridge National Lab., Jan. 30, 1958.

4. Sax, H. I. ; and Steinmetz, H.: Determination of Oxygen in Lithium Metal. Nuclear Development Corp. of America (AEC Rep. ORNL-2570), Oct. 31, 1958.

5. Gahn, Randall F.: Technique for Recovery of Alkali-Metal Reaction Products. NASA TN D-4310, 1968.

6. Swanson, H. E.; Morris, M. C.; Stinchfield, R.; and deGroot, J. H.: Standard $\mathrm{X}$-ray Diff raction Powder Patterns. Data for 46 Substances. Mono 25, Sec. 1, National Bureau of Standards, Mar. 9, 1962. 


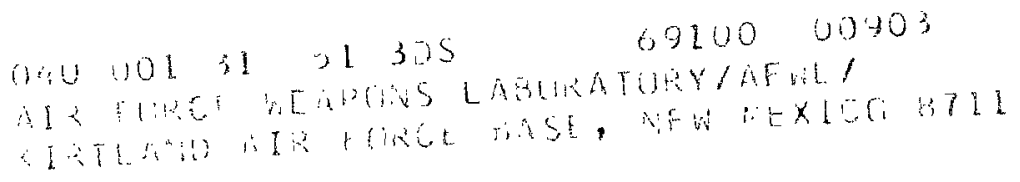

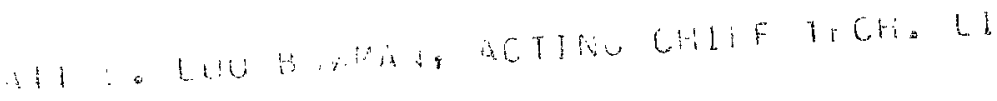

"The aeronautical and space activities of the United States shall be conducted so as to contribute... to the expansion of buman knowledge of phenomena in the atmosphere and space. The Administration shall provide for the widest practicable and appropriate dissemination of information concerning its activities and the results thereof."

- National Aeronautics ANd Space ACt of 1958

\section{NASA SCIENTIFIC AND TECHNICAL PUBLICATIONS}

TECHNICAL REPORTS: Scientific and technical information considered important, complete, and a lasting contribution to existing knowledge.

TECHNICAL NOTES: Information less broad in scope but nevertheless of importance as a contribution to existing knowledge.

\section{TECHNICAL MEMORANDUMS:}

Information receiving limited distribution because of preliminary data, security classification, or other reasons.

CONTRACTOR REPORTS: Scientific and technical information generated under a NASA contract or grant and considered an important contribution to existing knowledge.
TECHNICAL TRANSLATIONS: Information published in a foreign language considered to merit NASA distribution in English.

SPECIAL PUBLICATIONS: Information derived from or of value to NASA activities. Publications include conference proceedings, monographs, data compilations, handbooks, sourcebooks, and special bibliographies.

\section{TECHNOLOGY UTILIZATION}

PUBLICATIONS: Information on technology used by NASA that may be of particular interest in commercial and other non-aerospace applications. Publications include Tech Briefs, Technology Utilization Reports and Notes, and Technology Surveys.

Details on the availability of these publications may be obtained from:

\section{SCIENTIFIC AND TECHNICAL INFORMATION DIVISION}

\section{NATIONAL AERONAUTICS AND SPACE ADMINISTRATION \\ Washington, D.C. 20546}

